\title{
Effects of Slenderness Ratio on the Critical Flow Velocity of Fluid
}

\author{
G. I. Egu ${ }^{1}$, U. C. Okonkwo ${ }^{1}$, I.P. Okokpujie ${ }^{2}$, N.E. Udoye ${ }^{2}$ \\ ${ }^{1}$ Department of Mechanical Engineering, Nnamdi Azikiwe University, Awka \\ ${ }^{2}$ Department of Mechanical Engineering, Covenant University, Ota, Ogun State, Nigeria. \\ Email: imhade.okokpujie@covenantuniversity.edu.ng
}

\begin{abstract}
In this study, Fourier Half Range Series was used to analyse the internal flow-induced vibration in an undamped pinnedpinned pipe, in which the effects of varying slenderness ratios on the critical flow velocity were evaluated. A rigid polyvinylchloride material was used for the pipe. The fluidpipe system experiences gyroscopic damping arising from Coriolis force. The analysiswas carried out on pipes of span length $2 \mathrm{~m}$ with the following slenderness ratios $47.4,33.2$, $27.4,22.5,17.5$.The fluid used is water, an incompressible, non-volatile fluid flowing at room temperature. With the above slenderness ratio, the results of the critical velocity obtained were $16,20,22,24$, and $26 \mathrm{~m} / \mathrm{s}$, respectively. On a general note, the Fourier Half Range series solution showed that critical velocity increases with increasing slenderness ratio and vice versa.Furthermore, the fundamental frequency and amplitude beyond the critical velocityusing the slenderness ratios gave $0.0000+12.6469 \mathrm{i}, 0.0000+17.3228 \mathrm{i}$, $0.0000+16.8986 \mathrm{i}, \quad 0.0000+16.8039 \mathrm{i}, \quad 0.0000+14.3579 \mathrm{i}$ $(\mathrm{rad} / \mathrm{s})$ at velocities; 20, 22, 24, 25, $27 \mathrm{~m} /$ srespectively beyond the critical velocity. The fundamental frequencies were found to be purely imaginary beyond the critical velocity, producing complex amplitudes with very high real and imaginary components, which though purely ideal,indicate that in the unstable region, the pipe is heavily prone to failure.
\end{abstract}

Key words: Fourier Half Range Series, Pinned-Pinned Pipe, Critical Velocity, Slenderness Ratio, Frequency, Amplitude.

\section{INTRODUCTION}

The dynamic behaviour of fluid conveying pipes is more complicated than those of empty pipe without fluid, due to the internal forces developed from fluid-structure interaction in the former. The study of the vibration excitation forces from steady and unsteady flow, which produces the vibration in a fluid conveying pipe borders on three critical disciplines, on the structural mechanics, fluid dynamics, and mechanical vibration, is very significant.Blevins [1] derived an equation of motion for the transverse vibration of a simply supported pipe. Wiggert and Tijsseling [2] described fluid-structure interaction as any interaction that consists of the transfer of momentum and forces between piping and the contained liquid during unsteady flow. In the course of its flow, the flowing fluid imposes pressure on the walls of the pipe, which impacts stresses on the pipe material [3]. The resultant vibration of the pipe produced by lateral momentum of flowing fluid pushes the pipe to the point of instability beyond which it may fail, which has to lead to various researchersresearching the significance of mechanical engineering in fluid dynamics [4-6].

Morse [7] explained that internal flow-induced vibrations in pipes produce negative effects ranging from uncontrolled high stresses that cause sudden failures to persistent vibratory stresses that cause fatigue-related failures over time. The analysis was carried out with the vertical cantilever pipe fixed at the top, left open-ended,and at the bottom, were used for brine transportation. The author explained that brinewas discharged through the open end of the pipe at the bottom of the cavern. However, it decelerates, and the exiting flow induces a force on the pipe in the opposite direction. This force causes the hanging pipe to bend slightly, altering the direction of the discharge flow. Grant [8] employed finite element investigation methodology to define critical fluid velocity that brings the verge of pipe uncertainty while conducting two sequence of parametric studies on a constant and a variable wall thickness pipe, respectively. In a related study, Okonkwo et al.[9] applied the finite element method to analyse the internal flow-induced vibration in a pinned-pinned pipe, while studying the effects of increasing the length of the pipe span and the pipe bore diameter, on the critical flow velocity.

Ojetola et al. [10], while considering the effects of fluid mass and Coriolis acceleration, reported an analytical answer for the determination of normal frequencies, approach shapes, modal damagefeatures, and stability conditions of the pipe. Ali et al. [11] analysed the free vibration of pipes transporting fluid while resting on an elastic support. They calculated three eigenvalues of the Timoshenko beam for various values of stiffness and found that the natural frequency parameter was decreased with increasing values of mass ratio. Kokare and Paward[12], in their study of velocity and pressure distributions in fluid flow, found that natural frequencies of the pipe decreases with increasing thickness of cantilever pipe and increases with the thickness of clamped pipes. Mohamed et al. [13], employed Finite Element Analysis while studying the dynamic analysis of pipe conveying fluid stiffened by linear spring. They studied the effect of stiffness addition by a linear spring and the spring location, as well as the effect of flow velocity on the dynamic stability of the system. They found a spring constant at which the dynamic behaviour 
becomes sensitive, and that spring location depends on the flow velocity, and spring constant itself. Wen et al. [14] considered the effect of pipe wall thickness, fluid pressure, and fluid velocity while studying the fluid-structure interaction (FSI) behaviour of pipelines. They presented several pipeline schemes illustrating the application of the proposed method. Jweeg and Ntayeesh [15] developed a new approach using an experiment, for estimating the critical buckling velocities in pipes conveying fluid, for an increase in fluid pressure and have found fluid pressure to reduce critical velocity, as it increases, for clamped-pinned, pinned-pinned. Clamped-clamped pipes, Udoetok [16] proposed an equation for the maximum vibration velocity ofa fluid conveying pipe at critical velocity.

From literature, several portions of pipe and fluid parameters, and imposed conditions have been studied. The objective of this paper is to apply finite element modeling in the study of the effect of increasing the pipe span length and the pipe bore diameter on the critical velocity of fluid flow in a simply supported pipe.

\section{MATERIAL AND METHODS}

3.

The fluid conveying pipe is considered to be a uniform pipe of:

Length L, Internal perimeter S, transverse moment of inertia $\mathrm{I}$, and internal cross-sectional area $\mathrm{A}$, conveying fluid of mass per unit length $M=\rho A$ with a mean axial flow velocity $U$. The pipe is of rigid polyvinylchloride material of density $1390 \mathrm{~kg} / \mathrm{m}^{3}$, and the fluid is the water of density 999 $\mathrm{kg} / \mathrm{m}^{3}$ flowing at room temperature.

The equation of motion governing the vibration of the fluidpipe system is:

$\frac{E I \partial^{4} Y}{\partial x^{4}}+\frac{\rho A U^{2} \partial^{2} Y}{\partial x^{2}}+\frac{2 \rho A U \partial^{2} Y}{\partial x d t}+\frac{\&(\rho A+m) \partial^{2} Y}{\partial t^{2}}$

Where, $\rho \mathrm{A}=$ Fluid density $\mathrm{x}$ internal cross-sectional area, $m=$ mass of pipe per unit length

$\frac{E I \partial^{4} Y}{\partial x^{4}}$ is the stiffness term, which is known as a force acting on the pipe due to its bending

$\frac{\rho A U^{2} \partial^{2} Y}{\partial x^{2}}$ Is the curvature term, explained the force acting on the pipe, and conforming the flow of fluid to its curvature in the bend, $\frac{2 \rho A U \partial^{2} Y}{\partial x d t}$ is the Coriolis force term, a force required to rotate the fluid element as each point in the pipe span rotates with an angular velocity.

$\frac{(\rho A+m) \partial^{2} Y}{\partial t^{2}}$ It is the inertia force term, showing a force is acting on the pipe due to the inertia of the pipe and the fluid flowing through it.

$$
\begin{array}{lll}
\mathrm{L} & = & \text { Length of the pipe }(\mathrm{m}) \\
\rho & = & \text { Density of the fluid }\left(\mathrm{kg} / \mathrm{m}^{3}\right) \\
\mathrm{M} & = & \text { mass of the fluid per unit length }(\mathrm{kg} / \mathrm{m}) \\
\mathrm{m} & = & \text { mass of pipe per unit length }(\mathrm{kg} / \mathrm{m})
\end{array}
$$

$\begin{array}{lll}P & = & \text { Fluid applied pressure }\left(\mathrm{kg} / \mathrm{m}^{2}\right) \\ Y(x, t)= & \text { Expression for the lateral deformation of } \\ \text { the pipe } & \\ \mathrm{n} & = & \text { A set of integers } \\ \mathrm{k} & = & \text { A set of integers } \\ t & = & \text { time in seconds } \\ \mathrm{E} & = & \text { Young's Modulus }(\mathrm{GPa}) \\ \mathrm{I} & = & \text { Area moment of inertia } \\ \mathrm{U} & = & \text { Fluid Velocity }(\mathrm{m} / \mathrm{s}) \\ \omega & = & \text { frequency of vibration }(\mathrm{rad} / \mathrm{s}) \\ \bar{Y}(x) & = & \text { A set of sinusoidal mode shapes }\end{array}$

depending on the boundary condition.

\subsection{Solution by Fourier Series Expansion}

Equation (1) the governing equation of motion,

$\frac{E I \partial^{4} Y}{\partial x^{4}}+\frac{\rho A U^{2} \partial^{2} Y}{\partial x^{2}}+\frac{2 \rho A U \partial^{2} Y}{\partial x d t}+\frac{(\rho A+m) \partial^{2} Y}{\partial t^{2}}=0$

differs from other conventional vibration equations due to the presence of the mixed derivative term $\frac{\partial^{2} Y}{\partial x d t}$, although its effect is not the same as the viscous damping term of the form $\frac{\partial Y}{\partial t}$.

First, the equation of motion does not have normal classical modes due to the presence of the mixed derivative Coriolis force term $\left(\frac{2 \rho A U \partial^{2} Y}{\partial x d t}\right)$.Therefore, the solution of the equation of motion cannot be separated simply into time and space components as in classic beam vibration.

Adopting a trial solution:

However, we take a trial solution;

$Y(x, t)=\bar{Y}(x) \operatorname{Sin} \omega t$

Where $\bar{Y}(x)$ does a set of mode shapes depend on the boundary condition

Applying the Pinned-Pinned Boundary Condition:

For a pinned-pinned boundary condition:

The pinned-pinned boundary condition is satisfied by a set of sinusoidal mode shapes

$\bar{Y}(x)=\operatorname{Sin} \frac{n \pi x}{l}, \quad n=1,2,3, \ldots$

So that $\mathrm{A} 2$ can then be written as:

$Y(x, t)=\operatorname{Sin} \frac{n \pi x}{l} \operatorname{Sin} \omega t$

\subsection{Expression of the Equation of motion in terms of the trial solution and the applied Pinned-Pinned boundary condition}

Substituting (4) into (1), the mode shapes pass through the first, second, and last terms unaltered. However, the Coriolis force term varies as $\operatorname{Cos} \omega t$ (as against $\operatorname{Sin} \omega t$ in the other three terms). It generates spatially asymmetric terms for asymmetric mode shape and spatially symmetric terms for an asymmetric mode shape [1].

It is therefore considered that solution of the equation of motion will be the sum of symmetric and asymmetric spatial modes with sine and cosine time components, expressed in the form: 
G. I. Egu et al., International Journal of Emerging Trends in Engineering Research, 8(9), September 2020,6505 - 6511

$$
\begin{aligned}
& Y(x, t)=\sum_{n} A_{2 n-1} \operatorname{Sin}(2 n-1) \frac{\pi}{l} x \operatorname{Sin} \omega_{i} t+\sum_{k} A_{2 k} \operatorname{Sin} \frac{2 k \pi x}{l} \operatorname{Cos} \omega_{i} t \\
& (n=1,2,3, \ldots \& k=1,2,3, \ldots) \\
& \frac{\partial^{2} Y}{\partial x^{2}}=\sum_{n} A_{2 n-1}(2 n-1)^{2}\left(\frac{\pi}{l}\right)^{2} \operatorname{Sin}(2 n-1) \frac{\pi x}{l} \operatorname{Sin}\left(\omega_{i} t\right)+\sum_{k} A_{2 k}(2 k)^{2}\left(\frac{\pi}{l}\right)^{2} \operatorname{Sin} 2 k \frac{\pi x}{l} \operatorname{Cos}\left(\omega_{i} t\right)(7) \\
& \frac{\partial^{2} Y}{\partial x d t}=\sum_{n} A_{2 n-1}(2 n-1)\left(\frac{\pi}{l}\right)\left(\omega_{i}\right) \operatorname{Cos}(2 n-1) \frac{\pi}{l} x \operatorname{Cos}\left(\omega_{i} t\right)+\sum_{k} A_{2 k}(2 k)\left(\frac{\pi}{l}\right)\left(-\omega_{i}\right) \operatorname{Cos} 2 k \frac{\pi x}{l} \operatorname{Sin}\left(\omega_{i} t\right) \\
& \frac{\partial^{2} Y}{\partial t^{2}}=A_{2 n-1}\left(\omega_{i}{ }^{2}\right) \operatorname{Sin}(2 n-1) \frac{\pi}{l} x \operatorname{Sin}\left(\omega_{i} t\right)+A_{2 k}\left(-\omega_{i}{ }^{2}\right) \operatorname{Sin} 2 k \frac{\pi x}{l} \operatorname{Cos}\left(\omega_{i} t\right)(9) \\
& \frac{\partial^{4} Y}{\partial x^{4}}=\left\{\sum_{n} A_{2 n-1}(2 n-1)^{4}\left(\frac{\pi}{l}\right)^{4} \operatorname{Sin}(2 n-1) \frac{\pi x}{l} \operatorname{Sin}\left(\omega_{i} t\right)+\sum_{n} A_{2 k}(2 k)^{4}\left(\frac{\pi}{l}\right)^{4} \operatorname{Sin} 2 k \frac{\pi x}{l} \operatorname{Cos}\left(\omega_{i} t\right)\right\}(10)
\end{aligned}
$$

Substituting equations (7) to (10) into equation (1) we have:

$$
\begin{aligned}
& E I\left\{\sum_{n} A_{2 n-1}(2 n-1)^{4}\left(\frac{\pi}{l}\right)^{4} \operatorname{Sin}(2 n-1) \frac{\pi x}{l} \operatorname{Sin}\left(\omega_{i} t\right)+\sum_{n} A_{2 k}(2 k)^{4}\left(\frac{\pi}{l}\right)^{4} \operatorname{Sin} 2 k \frac{\pi x}{l} \operatorname{Cos}\left(\omega_{i} t\right)\right\} \\
+ & \rho A U^{2}\left\{\sum_{n} A_{2 n-1}(2 n-1)^{2}\left(\frac{\pi}{l}\right)^{2} \operatorname{Sin}(2 n-1) \frac{\pi x}{l} \operatorname{Sin}\left(\omega_{i} t\right)+\sum_{k} A_{2 k}(2 k)^{2}\left(\frac{\pi}{l}\right)^{2} \operatorname{Sin} 2 k \frac{\pi x}{l} \operatorname{Cos}\left(\omega_{i} t\right)\right\} \\
+ & 2 \rho A U\left\{\sum_{n} A_{2 n-1}(2 n-1)\left(\frac{\pi}{l}\right)\left(\omega_{i}\right) \operatorname{Cos}(2 n-1) \frac{\pi}{l} x \operatorname{Cos}\left(\omega_{i}\right)+\sum_{k} A_{2 k}(2 k)\left(\frac{\pi}{l}\right)\left(-\omega_{i}\right) \operatorname{Cos} 2 k \frac{\pi x}{l} \operatorname{Sin}\left(\omega_{i} t\right)\right\} \\
+(m+\rho A) & \left\{A_{2 n-1}\left(\omega_{i}{ }^{2}\right) \operatorname{Sin}(2 n-1) \frac{\pi}{l} x \operatorname{Sin}\left(\omega_{i} t\right)+A_{2 k}\left(-\omega_{i}{ }^{2}\right) \operatorname{Sin} 2 k \frac{\pi x}{l} \operatorname{Cos}\left(\omega_{i} t\right)\right\}=0
\end{aligned}
$$

The mixed derivative yields terms containing

$\operatorname{Cos}(2 n-1) \frac{\pi x}{l} \quad$ And $\operatorname{Cos}(2 k) \frac{\pi x}{l}$

There may be expanded in the Fourier half range series of sine functions over the length of the pipe from equation (11).

\subsection{Expansion of the Equation of motion by Fourier Half Range Series}

For the fundamental mode of period $2 l$, assuming an odd function, a Fourier sine series is obtained. The Fourier sine series has the general form:

$f(t)=\sum_{n=1}^{\infty} b_{n} \operatorname{Sin}\left(\frac{n \pi x}{l}\right)$

Where

$b_{n}=\frac{2}{l} \int_{0}^{l} f(x) \operatorname{Sin}\left(\frac{n \pi x}{l}\right)$

1st:

For $f(x)=\operatorname{Cos}(2 n-1) \frac{\pi x}{l}$;

$\operatorname{Cos}(2 n-1) \frac{\pi x}{l}=\sum_{q=1}^{\infty} b_{q} \operatorname{Sin}\left(\frac{q \pi x}{l}\right)$

$b_{q}=\frac{2}{l} \int_{0}^{l} \operatorname{Cos}(2 n-1) \frac{\pi x}{l} \times \operatorname{Sin}\left(\frac{q \pi x}{l}\right) d x$

$=\frac{1}{l} \int_{0}^{l}\left[\operatorname{Sin}(q+2 n-1) \frac{\pi x}{l}+\operatorname{Sin}(q-2 n+1) \frac{\pi x}{l}\right] d x$

$=\frac{1}{\pi}\left[-\frac{\operatorname{Cos}(q+2 n-1) \frac{\pi x}{l}}{q+2 n-1}-\frac{\operatorname{Cos}(q-2 n+1) \frac{\pi x}{l}}{q-2 n+1}\right]_{0}^{l}$

$=\frac{1}{\pi}\left\{-\frac{\operatorname{Cos}[q+(2 n-1)] \pi}{q+(2 n-1)}+\frac{1}{q+(2 n-1)}-\frac{\operatorname{Cos}[q-(2 n-1)] \pi}{q-(2 n-1)}+\right.$

$\left.\frac{1}{q-(2 n-1)}\right\}$

Where

$$
\begin{aligned}
\operatorname{Cos}[q \pm(2 n-1)] & \pi \\
& =\operatorname{Cos} q \pi \operatorname{Cos}(2 n-1) \pi \\
& \mp \operatorname{Sinq\pi } \operatorname{Sin}(2 n-1)
\end{aligned}
$$

$$
=-\operatorname{Cos} q \pi=\left\{\begin{array}{cl}
1 & \text { for odd } q \\
-1 & \text { for even } q
\end{array}\right.
$$

Substituting (16) into (15) yields

$$
\begin{aligned}
& b_{q}=\frac{2}{\pi}\left[\frac{1}{q+(2 n-1)}+\frac{1}{q-(2 n-1)}\right]_{q=2,4,6, \ldots} \\
& =\frac{2}{\pi}\left[\frac{q-(2 n-1)+q+(2 n-1)}{q^{2}-(2 n-1)^{2}}\right] \\
& =\frac{4}{\pi}\left[\frac{q}{q^{2}-(2 n-1)^{2}}\right] \\
& \text { Let } q=2 k \quad k=1,2,3, \ldots
\end{aligned}
$$

Substituting equation (18) into (17) yields

$b_{2 k}=\left[\frac{2 k}{(2 k)^{2}-(2 n-1)^{2}}\right]$

Substituting (19) into (14) yields

$\operatorname{Cos}(2 n-1) \frac{\pi x}{l}=\frac{4}{\pi} \sum_{k}^{\infty} \frac{2 k}{(2 k)^{2}-(2 n-1)^{2}} \operatorname{Sin} 2 k \frac{n \pi}{l}$

Where $n=1,2,3, \ldots$

And $k=1,2,3, \ldots$

2nd:

For $f(x)=\operatorname{Cos} \frac{(2 k) \pi x}{l}$

Then

$\operatorname{Cos} 2 k \frac{\pi x}{l}=\sum_{c=1}^{\infty} b_{c} \operatorname{Sin} \frac{c \pi x}{l}$

$b_{c}=\frac{2}{l} \int_{0}^{l}\left[\operatorname{Cos} \frac{(2 k) \pi x}{l} \times \operatorname{Sin} \frac{c \pi x}{l}\right] d x$

$=\frac{1}{l} \int_{0}^{l}\left[\operatorname{Sin}(c+2 k) \frac{\pi x}{l}+\operatorname{Sin}(c-2 k) \frac{\pi x}{l}\right] d x$

$=\frac{1}{\pi}\left[\frac{-\operatorname{Cos}(c+2 k) \frac{\pi x}{l}}{c+2 k}-\frac{\operatorname{Cos}(c-2 k) \frac{\pi x}{l}}{c-2 k}\right]_{0}^{l}$

$=\frac{1}{\pi}\left[\frac{-\operatorname{Cos}(c+2 k) \pi}{c+2 k}+\frac{1}{c+2 k}-\frac{\operatorname{Cos}(c-2 k) \pi}{c-2 k}+\frac{1}{c-2 k}\right](22)$ 
G. I. Egu et al., International Journal of Emerging Trends in Engineering Research, 8(9), September 2020, 6505 - 6511

Where

$\operatorname{Cos}[c \pm 2 k] \pi=\operatorname{Cos}(c \pi) \operatorname{Cos} 2 k \pi \mp \operatorname{Sin}(c \pi) \operatorname{Sin} 2 k \pi$

$=\operatorname{Cos}(c \pi)=\left\{\begin{array}{cc}-1 & \text { for odds } \\ 1 & \text { for evens }\end{array}\right.$

Substituting (23) into (22)

$b_{c}=\frac{2}{\pi}\left[\frac{1}{c+2 k}+\frac{1}{c-2 k}\right]$

$c=1,3,5, \ldots$

$=\frac{2}{\pi}\left[\frac{c-2 k+c+2 k}{c^{2}-(2 k)^{2}}\right]$

$=\frac{4}{\pi}\left[\frac{c}{c^{2}-(2 k)^{2}}\right]$

Let $c=2 n-1$

$n=1,2,3, \ldots$

Substituting (25) into (24) yields

$b_{2 n-1}=\frac{4}{\pi}\left[\frac{2 n-1}{(2 n-1)^{2}-\left(2 k^{2}\right)}\right]$
$\operatorname{Cos}(2 k) \frac{\pi x}{l}=\frac{4}{\pi} \sum_{k}^{\infty} \frac{2 n-1}{(2 n-1)^{2}-(2 k)^{2}} \operatorname{Sin}(2 n-1) \frac{\pi x}{l}(27)$

Where $k=1,2,3, \ldots$

And $n=1,2,3, \ldots$

The expansion of $\operatorname{Cos}(2 n-1) \frac{\pi x}{l}$ yields

$\operatorname{Cos}(2 n-1) \frac{\pi x}{l}=\frac{4}{\pi} \sum_{k}^{\infty} \frac{2 k}{(2 k)^{2}-(2 n-1)^{2}} \operatorname{Sin} 2 k \frac{n \pi}{l}(28)$

And the expansion of $\operatorname{Cos}(2 k) \frac{\pi x}{l}$ yields:

$\operatorname{Cos}(2 k) \frac{\pi x}{l}=\frac{4}{\pi} \sum_{n}^{\infty} \frac{2 n-1}{(2 n-1)^{2}-(2 k)^{2}} \operatorname{Sin}(2 n-1) \frac{\pi x}{l}(29)$

Where $n=1,2,3, \ldots$

and $k=1,2,3, \ldots$ in each case.

Substituting equation (28) and (29) into (11) yields

Substituting (26) into (21) yields

$$
\begin{aligned}
& E I\left\{\sum_{n} A_{2 n-1}(2 n-1)^{4}\left(\frac{\pi}{l}\right)^{4} \operatorname{Sin}(2 n-1) \frac{\pi x}{l} \operatorname{Sin}\left(\omega_{i} t\right)+\sum_{n} A_{2 k}(2 k)^{4}\left(\frac{\pi}{l}\right)^{4} \operatorname{Sin} 2 k \frac{\pi x}{l} \operatorname{Cos}\left(\omega_{i} t\right)\right\} \\
+ & \rho A U^{2}\left\{\sum_{n} A_{2 n-1}(2 n-1)^{2}\left(\frac{\pi}{l}\right)^{2} \operatorname{Sin}(2 n-1) \frac{\pi x}{l} \operatorname{Sin}\left(\omega_{i} t\right)+\sum_{k} A_{2 k}(2 k)^{2}\left(\frac{\pi}{l}\right)^{2} \operatorname{Sin} 2 k \frac{\pi x}{l} \operatorname{Cos}\left(\omega_{i} t\right)\right\} \\
+ & 2 \rho A U\left\{\sum_{n} A_{2 n-1}(2 n-1)\left(\frac{\pi}{l}\right)\left(\omega_{i}\right) \frac{4}{\pi} \sum_{k}^{\infty} \frac{2 k}{(2 k)^{2}-(2 n-1)^{2}} \operatorname{Sin} 2 k \frac{n \pi}{l} \operatorname{Cos}\left(\omega_{i} t\right)\right. \\
- & \left.-\sum_{k} A_{2 k}(2 k)\left(\frac{\pi}{l}\right)\left(\omega_{i}\right) \frac{4}{\pi} \sum_{n}^{\infty} \frac{2 n-1}{(2 n-1)^{2}-(2 k)^{2}} \operatorname{Sin}(2 n-1) \frac{\pi x}{l} \operatorname{Sin}\left(\omega_{i} t\right)\right\}
\end{aligned}
$$

\subsection{Generation of the Characteristic Equation:}

Collecting like groups of sine and cosine terms, and equating coefficients of each group to zero to satisfy equation (1), yields the equations [18].

$A_{2 n-1}=\sum_{k} A_{2 k} \frac{E I(2 k)^{4}\left(\frac{\pi}{l}\right)^{4}-\rho A U^{2}(2 k)^{2}\left(\frac{\pi}{l}\right)^{2}-(m+\rho A)\left(\omega_{i}^{2}\right)}{16 \rho A U \omega_{i}\left(\frac{k}{l}\right)(2 n-1) /\left[(2 n-1)^{2}-(2 k)^{2}\right]}(31)$

$A_{2 k}=\sum_{n} A_{2 n-1} \frac{16 \rho A U \omega_{i}\left(\frac{k}{l}\right)(2 n-1) /\left[(2 n-1)^{2}-(2 k)^{2}\right]}{E I(2 k)^{4}\left(\frac{\pi}{l}\right)^{4}-\rho A U^{2}(2 k)^{2}\left(\frac{\pi}{l}\right)^{2}-(m+\rho A)\left(\omega_{i}{ }^{2}\right)}(32)$

$\left\{16 E I\left(\frac{\pi}{l}\right)^{4}-4 \rho A U^{2}\left(\frac{\pi}{l}\right)^{2}-(m+\rho A)\left(\omega_{i}\right)^{2}\right\}\left\{E I\left(\frac{\pi}{l}\right)^{4}-\rho A U^{2}\left(\frac{\pi}{l}\right)^{2}-(m+\rho A)\left(\omega_{i}\right)^{2}\right\}=\left(\frac{16 \rho A U\left(\omega_{i}\right)}{3 L}\right)^{2}(35)$

Which is rewritten as:

$\left\{16 E I\left(\frac{\pi}{l}\right)^{4}-4 \rho A U^{2}\left(\frac{\pi}{l}\right)^{2}-(m+\rho A)\left(\omega_{i}\right)^{2}\right\}\left\{E I\left(\frac{\pi}{l}\right)^{4}-\rho A U^{2}\left(\frac{\pi}{l}\right)^{2}-(m+\rho A)\left(\omega_{i}\right)^{2}\right\}-\left(\frac{16 \rho A U\left(\omega_{i}\right)}{3 L}\right)^{2}=0 .(36)$

And expands to:

$$
\begin{aligned}
(m+\rho A)\left(\omega_{i}\right)^{4}+ & \left\{(m+\rho A) \rho A U^{2}\left(\frac{\pi}{l}\right)^{2}-\frac{16 \rho A U}{3 L}+(m+\rho A) \rho A U^{2}\left(\frac{\pi}{l}\right)^{2}-4 \rho A U^{2}\left(\frac{\pi}{l}\right)^{2}(m+\rho A)-16 E I(m+\rho A)\left(\frac{\pi}{l}\right)^{4}\right. \\
& \left.-E I(m+\rho A)\left(\frac{\pi}{l}\right)^{4}\right\}\left(\omega_{i}\right)^{2}+(16 E I)^{2}\left(\frac{\pi}{l}\right)^{8}-16 E I \rho A U^{2}\left(\frac{\pi}{l}\right)^{6}-4 E I \rho A U^{2}\left(\frac{\pi}{l}\right)^{6}+4 \rho A U^{2}\left(\frac{\pi}{l}\right)^{4}=0
\end{aligned}
$$

Of which equation (37) can be written in simple terms of a quadratic equation for the fundamental mode as:
Substituting (34) into (33) and eliminating $A_{1}$, yields the characteristic equation

Expanding (31) and (32) for $n=1,2,3$ and $k=1,2,3$, and then suppressing all modes except the first two modes

$$
\begin{aligned}
& A_{1}=A_{2} \frac{\left(-\frac{16}{3}\right) \rho A U\left(\omega_{i}\right) / L}{E I\left(\frac{\pi}{l}\right)^{4}-\rho A U^{2}\left(\frac{\pi}{l}\right)^{2}-(m+\rho A)\left(\omega_{i}\right)^{2}} \\
& A_{2}=A_{1} \frac{\left(-\frac{16}{3}\right) \rho A U\left(\omega_{i}\right) / L}{16 E I\left(\frac{\pi}{l}\right)^{4}-4 \rho A U^{2}\left(\frac{\pi}{l}\right)^{2}-(m+\rho A)\left(\omega_{i}\right)^{2}}
\end{aligned}
$$


G. I. Egu et al., International Journal of Emerging Trends in Engineering Research, 8(9), September 2020, 6505 - 6511

$$
\begin{aligned}
& (m+\rho A)\left(\omega^{2}\right)^{2}+\left\{(m+\rho A) \rho A U^{2}\left(\frac{\pi}{l}\right)^{2}-\frac{16 \rho A U}{3 L}+(m+\rho A) \rho A U^{2}\left(\frac{\pi}{l}\right)^{2}-4 \rho A U^{2}\left(\frac{\pi}{l}\right)^{2}(m+\rho A)-16 E I(m+\rho A)\left(\frac{\pi}{l}\right)^{4}-\right. \\
& \left.E I(m+\rho A)\left(\frac{\pi}{l}\right)^{4}\right\}\left(\omega^{2}\right)+(16 E I)^{2}\left(\frac{\pi}{l}\right)^{8}-16 E I \rho A U^{2}\left(\frac{\pi}{l}\right)^{6}-4 E I \rho A U^{2}\left(\frac{\pi}{l}\right)^{6}+4 \rho A U^{2}\left(\frac{\pi}{l}\right)^{4}=
\end{aligned}
$$

And solved as a quadratic equation of roots $\omega^{2}$ so that the value of fundamental frequency $\omega$ is obtained as the square $\operatorname{root} \sqrt{\omega^{2}}$ of the original root $\omega^{2}$.

The amplitudes are also obtained by substituting the value of $\omega$ into (33) and (34) along with other parameters. Finally, equation (6) is plotted for some time of $t=1$ to 400 seconds, in the fundamental mode.

\section{RESULTS AND DISCUSSION}

The pipe parameters, pipe length, pipe density, elastic modulus, pipe diameter, and slenderness ratio of the pipe were defined. Likewise, the fluid parameters, fluid density, and fluid velocity were defined. Both were imported into the characteristic equation (38), which was solved using the Fourier half range series for fundamental frequency $(\omega)$ and amplitude at various values of fluid velocity (U), from $U=0$ to the critical velocity $\mathrm{U}=\mathrm{U}_{\text {crit. }}$.

An extra step was taken by obtaining the fundamental frequency and amplitude for a fluid velocity value higher than the critical. For each pipe, the fundamental frequency at $\mathrm{U}=0$ was obtained as the natural frequency of the fluid conveying pipe, and the fluid velocity at which the fundamental frequency $\omega=0$, was obtained as the critical velocity of the fluid-pipe system. In line with this, the values of the critical velocity $\left(\mathrm{U}_{\text {crit }}\right)$ were collected for each pipe of the given slenderness ratio. The following pipe slenderness ratios were analysed: $47.4,33.2,27.4,22.5,17.5$.

consistent reduction for real Eigen frequencies from fluid velocity $U=0$ to the critical velocity at $\omega=0$. This is because, at zero fluid velocity, the pipe vibrates strictly under its weight, depending solely on its mass and stiffness without the influence of the lateral momentum of the fluid. Furthermore, the fluid velocity-dependent and takes effect as soon as the fluid in the pipe gains velocity up until the critical point of instability at the critical flow velocity.

Subsequently, there is a transformation into purely imaginary eigenfrequencies beyond the critical velocity for each of the pipes. This is in total agreement with Paidoussis
[17]. The pipes of slenderness ratios: 47.4, 33.2, 27.4, 22.5, 17.5 have their corresponding critical velocities at 16,20 , 22,24 , and 26 meters per second, respectively, as shown in Table 1.

Table 2 presents the distribution of amplitudes with increasing fluid velocity. A common observation is that the amplitudes increase by small margins with increasing fluid velocity. However, while approaching the critical velocity, there is a sudden decline in its development as it hits zero at the critical velocity only to overshoot astronomically immediately the critical velocity is exceeded. At this point, the amplitude becomes complex comprising of very high magnitude real and imaginary components.

This complex amplitude beyond the critical velocity indicates that the wave of oscillation contains both stationary and traveling wave components. Before the critical velocity, the magnitude of the imaginary component of the wave of oscillation is infinitesimally small, amounts to no significance, and is therefore neglected. This is why the amplitudes before the critical velocity are recorded as purely real. However, beyond the critical velocity, the imaginary component of amplitude appears very significantly in the unstable region where the pipe seeks equilibrium at either side of the pipe in a pitchfork bifurcation or at any other position away from its original equilibrium position. Beyond just suffering a deformation, the pipe could probably fail in this region.

The slenderness ratios 47.4, 33.2, 27.4, 22.5, 17.5, have complex amplitudes $(7.808-1.563 i) \times 10^{303},(8.3409-$ $1.4773 \mathrm{i}) \times 10^{304},(-2.8240+4.709 \mathrm{i}) \times 10^{302},(-2.2834+$ $3.8846 \mathrm{i}) \times 10^{301},(-1.7940+2.9612 \mathrm{i}) \times 10^{300} \mathrm{~mm}$,

respectively, at the following corresponding fluid velocities, $18,22,24,25,27 \mathrm{~m} / \mathrm{s}$. With the slenderness ratio reducing, there is a consequent increase in the value of critical velocity. The slenderness ratio reduction also yields an increase in mass per unit length of the pipe, with an overall increase in the mass ratio of the fluid pipe system. This provides the pipe material with significant resistance to forces exerted by the momentum of fluid, which produces the vibration [18-20].

\begin{tabular}{|c|c|c|c|c|c|c|c|}
\hline \multirow{2}{*}{$\begin{array}{l}\text { Fluid } \\
\text { Velocity (U) } \\
(\mathrm{m} / \mathrm{s})\end{array}$} & \multicolumn{7}{|c|}{ Frequency $(\mathrm{rad} / \mathrm{s})$ at various slenderness ratios } \\
\hline & 47.4 & 33.2 & & & 22.5 & & \\
\hline 0 & 24.62 & & 29.74 & 33.1 & & 37.39 & 42.78 \\
\hline 2 & 24.36 & & 29.53 & 32.91 & & 37.21 & 42.62 \\
\hline 4 & 23.62 & & 28.9 & 32.33 & & 36.68 & 42.14 \\
\hline 6 & 22.38 & & 27.85 & 31.36 & & 35.78 & 41.34 \\
\hline 8 & 20.61 & & 26.36 & 29.98 & & 34.51 & 40.21 \\
\hline 10 & 18.2 & & 24.38 & 28.17 & & 32.85 & 38.74 \\
\hline 12 & 14.96 & & 21.83 & 25.88 & & 30.76 & 36.91 \\
\hline
\end{tabular}

Table 1: Frequency (rad/s) at Slenderness Ratios, 47.4, 33.2, 27.4, 22.5, 17.5 for Fluid Velocities 0 to 28 m/s. 
G. I. Egu et al., International Journal of Emerging Trends in Engineering Research, 8(9), September 2020,6505 - 6511

\begin{tabular}{rrrrrr}
\hline 14 & 6.47 & 18.55 & 23 & 28.19 & 34.68 \\
16 & 0 & 14.13 & 19.35 & 25.03 & 32.01 \\
18 & $0.0000+12$. & 6.71 & 14.41 & 21.08 & 28.81 \\
20 & $6469 \mathrm{i}$ & 0 & 5.57 & 15.8 & 24.91 \\
22 & & $0.0000+17.3228 \mathrm{i}$ & 0 & 6.7 & 19.95 \\
24 & & $0.0000+16.8986 \mathrm{i}$ & 0 & 12.82 \\
25 & & & $0.0000+16.8039 \mathrm{i}$ & 0.64 \\
26 & & & & $0.0000+14.357$ \\
27 & & & & $9 \mathrm{i}$ \\
28 & & & & \\
\end{tabular}

Table 2: Amplitude (mm) at Slenderness Ratios, 47.4, 33.2, 27.4, 22.5, 17.5 for Fluid Velocities 0 to $28 \mathrm{~m} / \mathrm{s}$.

\begin{tabular}{|c|c|c|c|c|c|}
\hline \multirow{2}{*}{$\begin{array}{l}\text { Fluid } \\
\text { Velocity } \\
\text { (U) } \\
(\mathrm{m} / \mathrm{s})\end{array}$} & \multicolumn{5}{|c|}{ Amplitude $(\mathrm{mm})$ at various slenderness ratios } \\
\hline & 47.4 & 33.2 & 27.4 & 22.5 & 17.5 \\
\hline 0 & 0 & 0 & 0 & 0 & 0 \\
\hline 2 & $\begin{array}{l}0.98013 \\
\times 10^{-4}\end{array}$ & $\begin{array}{l}0.8689 \\
\times 10^{-4}\end{array}$ & $0.7839 \times 10^{-4}$ & $0.73255 \times 10^{-4}$ & $0.6568 \times 10^{-4}$ \\
\hline 4 & $\begin{array}{l}1.843 \\
\times 10^{-4}\end{array}$ & $\begin{array}{l}1.6634 \\
\times 10^{-4}\end{array}$ & $1.5507 \times 10^{-4}$ & $1.4186 \times 10^{-4}$ & $1.2812 \times 10^{-4}$ \\
\hline 6 & $\begin{array}{l}2.5346 \\
\times 10^{-4} \\
\end{array}$ & $\begin{array}{l}2.326 \\
\times 10^{-4} \\
\end{array}$ & $2.1929 \times 10^{-4}$ & $2.0279 \times 10^{-4}$ & $1.8481 \times 10^{-4}$ \\
\hline 8 & $\begin{array}{l}3.0285 \\
\times 10^{-4}\end{array}$ & $\begin{array}{l}2.8499 \\
\times 10^{-4}\end{array}$ & $2.7148 \times 10^{-4}$ & $2.5433 \times 10^{-4}$ & $2.3415 \times 10^{-4}$ \\
\hline 10 & $\begin{array}{l}3.3136 \\
\times 10^{-4}\end{array}$ & $\begin{array}{l}3.2288 \\
\times 10^{-4}\end{array}$ & $3.1214 \times 10^{-4}$ & $2.9623 \times 10^{-4}$ & $2.7634 \times 10^{-4}$ \\
\hline 12 & $\begin{array}{l}3.2525 \\
\times 10^{-4}\end{array}$ & $\begin{array}{l}3.4388 \\
\times 10^{-4}\end{array}$ & $3.397 \times 10^{-4}$ & $3.2823 \times 10^{-4}$ & $3.1066 \times 10^{-4}$ \\
\hline 14 & $\begin{array}{l}1.7963 \\
\times 10^{-4}\end{array}$ & $\begin{array}{l}3.4089 \\
\times 10^{-4}\end{array}$ & $3.5091 \times 10^{-4}$ & $3.4894 \times 10^{-4}$ & $3.3696 \times 10^{-4}$ \\
\hline 16 & 0 & $\begin{array}{l}2.9765 \\
\times 10^{-4}\end{array}$ & $3.3795 \times 10^{-4}$ & $3.5457 \times 10^{-4}$ & $3.5399 \times 10^{-4}$ \\
\hline 18 & $\begin{array}{l}(7.808- \\
1.563 \mathrm{i}) \\
\times 10^{303}\end{array}$ & $\begin{array}{l}1.5916 \\
\times 10^{-4}\end{array}$ & $2.8426 \times 10^{-4}$ & $3.3784 \times 10^{-4}$ & $3.5812 \times 10^{-4}$ \\
\hline 20 & & 0 & $1.2219 \times 10^{-4}$ & $2.8342 \times 10^{-4}$ & $3.4643 \times 10^{-4}$ \\
\hline 22 & & $\begin{array}{l}(8.3409- \\
1.4773 \mathrm{i}) \\
\times 10^{304}\end{array}$ & 0 & $1.3288 \times 10^{-4}$ & $3.0715 \times 10^{-4}$ \\
\hline 24 & & & $\begin{array}{l}(-2.8240+4.709 i) \\
x 10^{302}\end{array}$ & 0 & $2.1654 \times 10^{-4}$ \\
\hline 25 & & & & $\begin{array}{l}(-2.2834+3.8846 \mathrm{i}) \\
\mathrm{x} 10^{301}\end{array}$ & $1.1703 \times 10^{-4}$ \\
\hline 26 & & & & & 0 \\
\hline 27 & & & & & $\begin{array}{l}(-1.7940+2.9612 \mathrm{i}) \\
\mathrm{x} 10^{300}\end{array}$ \\
\hline
\end{tabular}

\section{CONCLUSION}

From the results of the analysis of internal flow-induced vibration in a pinned-pinned pipe carried out using the
Fourier half range series; the following conclusions can be drawn:

i. There is a steady reduction in the fundamental frequency of the pipe with an increase in flow velocity up to the critical velocity, where the 
fundamental frequency eventually drops to zero.

ii. The slenderness ratio of the pipe affects critical flow velocity, and the result shows that the higher the slenderness ratio, the lower the critical velocity. Conversely, a lower slenderness ratio yields a higher critical flow velocity.

iii. Extremely high complex amplitudes indicate that the pipe becomes very unstable, is highly prone to failure, and may fail at a velocity above its critical velocity.

\section{ACKNOWLEDGMENT}

The authors wish to acknowledge the covenant university management for their constant support

\section{REFERENCES}

1. R.D. Blevins.Flow-Induced Vibration.(2nd edition). New York: Van Nostrand Reinhold(1990).

2. D.C. Wiggert, \& A .S.Tijsseling. Fluid transients and Fluid-Structure Interaction In Flexible Liquid-Filled Piping.Applied Mechanics Reviews 2001. 54, 455 481.

3. N.O.Ubani,J. E.Dara,U. C.Okonkwo,B. N. Nwankwojike, C. Iheakaghichi. Water pipeline network analysis using simultaneous loop flow correction method.West African Journal of Industrial and Academic Research 6(1): 4 - 22. 2013.

4. I. P.Okokpujie, O. S. I.Fayomi, \&S. O. Oyedepo. The Role of Mechanical Engineers in Achieving Sustainable Development Goals. Procedia Manufacturing. 35, 782-788.2019.

5. I. P.Okokpujie, O. S.Fayomi, \&R. O. Leramo. The Role of Research in Economic Development. InIOP Conference Series. Materials Science and Engineering, 12060. 2018.

6. I. P. Okokpujie, O. S. I. Fayomi, S. K.Ogbonnaya, \&G. U. Fayomi. The Wide Margin Between the Academic and Researcher in a New Age University for Sustainable Development. Energy procedia, 157, 862870, 2019

7. T.L. Morse. Flow-Induced Vibration of a Vertical Pipe: Limitations on Gas Extraction Flow Rates. Exponent Oil and Gas Insight, Vol. 2. 2008.

8. I. Grant.Flow-induced vibrations in pipes, a finite element approach (Masters Thesis, Cleveland State University, Ohio, United States of America ). Retrieved from: http://etd.ohiolink.edu/!etd._2010.

9. U. C.Okonkwo, G. I. O.Egu,C. Samuel. Analysis of the Effects of Pipe Specifications on the Critical Flow
Velocity of Fluid. Journal of Engineering and Applied Sciences 16 (1). 98-107, 2020.

10. A. Ojetola, N. J.Jameson, and H.R. Hamidzadeh. Flow-induced vibration and critical velocities. Proceedings of the ASME 2011 International Design Engineering Technical Conference IDETC/CIE. 2011.

11. H.Ali, T.J. Al- Hilli\&Ntayeesh. Free vibration characteristics of elastically supported pipe conveying fluid, Nahrain University College Of Engineering Journal (NUCEJ), vol.16. 2013.

12. A.B. Kokare, \&P.M. Paward. Vibration characteristics of pipe conveying fluid.Journal of Scientific Engineering and Technology Research, 4(51), pp (10951-10954). 2015.

13. J. A.Mohamed, Q. Mohammed, \&R. Hatem. Stability analysis of pipe conveying fluid stiffened by linear stiffness. International Journal of Current Engineering and Technology, 6(5), 2016.

14. L.Wen, L. Gonguin, \&W. Hoaran. Dynamic analysis of pipes conveying fluid by transfer matrix method.Paper presented at the $23^{\text {rd }}$ International Conference on Sound and Vibration, Athens, Greece. 2016.

15. M.J. Jweeg, \&T.J. Ntayeesh. Determination of critical buckling velocities of pipes conveying fluid rested on different support conditions. International Journal of Computer Applications, 134(10),34-42, 2016. Retrieved

from:http://www.ijcaonline.org/archives/volume134/nu mber10/23954-2016908204

16. E.S. Udoetok. Internal Fluid Flow Induced vibration of Pipes.Journal of Mechanical Design and vibration,vol6(1), 1-8, 2018.

17. M.P.Paidoussis. Fluid-Structure Interactions, slender structures, and axial flow, vol. 1. London: Elsevier Academic Press. 1998

18. M .R. Xu, S.P. Xu, \&H.Y. Guo. Determination of natural frequencies of fluid-conveying pipes using the homotopy perturbation method.Computers \& Mathematics with Applications 60, 520-52, 2010.

19. O. I. Vaganova1, E. V. Vezetiu, Z. V. Smirnova, A. V. Lapshova, E. A. Chelnokova. Investigation of the influence of heating temperature on the hardness of heat-treated tool steel.International Journal of Emerging Trends in Engineering Research.Volume 8. No. 7, July 2020

20. H. Mohapatra, S. Panda, A. K. Rath, S.A. Edalatpanah, R. Kumar. A Tutorial on PowerShell Pipeline and its Loopholes. International Journal of Emerging Trends in Engineering Research. Volume 8. No. 4, April 2020. https://doi.org/10.30534/ijeter/2020/06842020 